\title{
CERTAIN INEQUALITIES AND THEIR APPLICATIONS TO MULTIVALENTLY ANALYTIC FUNCTIONS
}

\author{
HÜSEYIN IRMAK
}

\begin{abstract}
In the present investigation, by making use of fractional calculus operator, two theorem involving certain inequalities of multivalent functions and their derivatives which are analytic in the open unit disk are stated. In addition, some interesting and/or mentioned results which will be important for Analytic and Geometric Function Theory (see, [1], [4], and also [2]) are also pointed.
\end{abstract}

\section{Mathematics subject classification (2000): 30C45, 26A33, 33C20.}

Key words and phrases: Multivalently analytic function, multivalently starlike function, multivalently convex function, multivalently close-to-convex function, unit open disk, fractional calculus, principal values, inequalities, Jack's Lemma.

\section{REFERENCES}

[1] A. W. Goodman, Univalent Functions Vols. I and II, Polygonal Publishing House, Washington, New Jersey (1983).

[2] H. M. SRIVAStava, S. Owa, Current Topics in Analytic Function Theory, World Scientific Publishing Company, Singapore, New Jersey, London, and Hong Kong (1992).

[3] I. S. JACK, Functions starlike and convex of order $\alpha$, J. London Math. Soc. 3 (1971), 469-474.

[4] P. L. DuREN, Univalent Functions, Grundlehren der Mathematischen Wissenschaften 259, Springer-Verlag, New York, Heidelberg and Tokyo (1983).

[5] S. OwA, On the distortion theorems. I, Kyungpook Math. J. 18 (1978), 53-59.

[6] S. OWA, H. M. SRIVASTAVA, Univalent and starlike generalized hypergeometric functions, Canad. J. Math. 39 (1987), 1057-1077.

[7] H. IRMAK, R. K. RaINA, Some applications of generalized fractional calculus operators to a novel class of analytic functions with negative coefficients, Taiwanese J. Math. 8 (2004), 443-452.

[8] H. IrmaK, G. TinAZTEPE, Y. C. Kim AND J. H. ChOI, Certain classes and inequalities involving fractional calculus and multivalent functions, Fract. Calc. Appl. Anal. 5 (2002), 267-274.

[9] M. P. Chen, H. IRmaK AND H. M. SRIVASTAVA,, Some families of multivalently analytic functions with negative coefficients, J. Math. Anal. Appl. 214 (1997), 674-690. 